\title{
La sensibilidad humana. Su presencia en las cartas de José Martí de 1895
}

\section{Human sensitivity. Its presence in the letters of José Martí of $1895^{1}$}

Recibido: 12 de noviembre de 2015- Revisado: 28 de abril de 2016 - Aceptado: 22 de junio de 2016.

\section{Freddy Varona Domínguez ${ }^{2}$}

\section{Resumen}

La base teórica del texto está en la urgencia que tiene la humanidad de luchar por el enriquecimiento del universo espiritual y contra la indiferencia ante los problemas. Desarrolla dos núcleos temáticos relacionados entre sí: uno, la categoría sensibilidad humana, de la cual ofrece consideraciones y rasgos, como la conjugación sentimientorazón y la emisión de respuestas ante los estímulos; dos, la presencia de esta categoría en las cartas que el pensador y patriota cubano José Martí (1853-1895) escribe durante 1895.

Palabras clave

Universo espiritual, sensibilidad humana, pensamiento cubano.

\section{Abstract}

The theoretical basis of the text lies in the urgency of humanity to fight for the enrichment of the spiritual universe and against indifference to problems. It develops two thematic nuclei related to each other: one, the category human sensitivity, which offers considerations and features, such as the feeling-reason conjugation and the emission of responses to the stimuli; two, the presence of this category in the letters that the Cuban thinker and patriot Jose Marti (1853-1895) writes during 1895.

\section{Keywords}

Spiritual universe, human sensitivity, Cuban thought.

\footnotetext{
${ }^{1}$ Artículo de investigación de la línea investigativa "La producción espiritual en el pensamiento cubano", del proyecto de investigación científica "Diálogos marxistas", aprobado para el período 2014-2017 en la Facultad de Filosofía e Historia de la Universidad de La Habana, Cuba.

${ }^{2}$ Doctor en Ciencias Filosóficas. Profesor Titular de la Universidad de La Habana, La Habana, Cuba. Sus líneas de investigación más recientes son: El humanismo. Su presencia en el pensamiento cubano (siglos XIX-XX); El pensamiento complejo y la transdisciplinariedad: desafíos en la educación superior; Cultura y educación estética. Estudios filosóficos.

Correo electrónico: fvarona@ffh.uh.cu Para citar este artículo use: Varona, F. (2017). La sensibilidad humana. Su presencia en las cartas de José Martí de 1895. Civilizar Ciencias Sociales y Humanas, 17(32),197-208. Doi: $10.22518 / 16578953.826$
} 


\section{Introducción}

A mediados de la segunda década del siglo XXI no han disminuido los problemas que desde hace tiempo aquejan a la humanidad, ni siquiera en los países más desarrollados; antes bien, empeoran los niveles económicos y de seguridad social (Díez, 2011, p. 16), "el egoísmo, la violencia y la mezquindad espiritual parecen socavar la bondad de nuestra vida colectiva" (Goleman, s.f., p. 6), aumenta la agresividad y otros problemas emocionales (p. 10). Se hacen característicos hechos como: la industrialización de las relaciones sentimentales-sexuales mediante los encuentros digitales -una especie de mercado de relaciones sexuales rápidas (Lardellier, 2014, p. 79); el incremento de parejas flexibles y efímeras (Venegas, 2011, p. 576); la atención al cuerpo como un accesorio para moldear, en un marco de belleza donde no importa la salud (Espinal, Estrada, \& Pérez 2012, p. 190), sino la moda (Retana, 2014, p. 326); la sobrevaloración de los bienes materiales; el aumento de la atención a lo banal y chabacano; "la indiferencia recíproca y [...] el individualismo de masa" (Bodei, 1995, p. 6). A su vez, crece la indolencia ante ideas y hechos que engendran odio y discriminación, degeneran a los humanos y atentan contra su mejoramiento, o dañan el planeta. Algunos de esos problemas, fatalmente, también se incrementan en Cuba.

La búsqueda y hallazgo de las soluciones a esos problemas y otros, debe hacerse creativamente; esto incluye que se haga con todo el universo espiritual, entendido este como la producción, difusión, consumo, cambio y conservación de ideas, teorías, creencias, sentimientos, valores, ideales, que se realiza en la ciencia, la religión, la filosofía, la política, la literatura, la moral, la estética, relacionado con las necesidades, los intereses, los fines y la actividad correspondiente. Sobre esta base se apela a la categoría sensibilidad humana con un significado no habitual y se presenta con la intención de contribuir a su desarrollo teórico, que se puede alcanzar de diversas maneras; una es el uso de textos, ya sea donde se reflexiona acerca de ella o donde se manifiesta o incita; en estos últimos casos están los del pensador y patriota cubano José Martí (1853-1895).

Resultados: contribución al despliegue teórico de la categoría sensibilidad humana; muestra de la presencia de la sensibilidad humana de José Martí en las cartas de 1895.

Problemas de investigación: el despliegue teórico de la categoría sensibilidad humana; la manifestación de la sensibilidad humana de José Martí en las cartas de 1895.

Objetivos: contribuir al despliegue teórico de la categoría sensibilidad humana; mostrar la manifestación de la sensibilidad humana de José Martí en las cartas de 1895.

Enfoque metodológico: estudio crítico de textos. Métodos: análisis-síntesis (para determinar las ideas contributivas con el objeto de estudio); inducción-deducción (para determinar los límites de los estudios realizados sobre el tema, deducir los elementos particulares investigados y llegar a conclusiones); históricológico (para atender las condiciones históricas y la coherencia temática); conjugación de lo universal y lo particular (para tener en cuenta lo común y lo específico) y comparación (de ideas, textos, etc.).

Tipo de investigación: teórica (se desarrolló en un amplio marco bibliográfico).

Estrategia seguida: se decidió que para contribuir al desarrollo teórico de la categoría sensibilidad humana era oportuno usar una bibliografía diversa. Se determinó que un ejemplo de sensibilidad humana e incitación a ella es el pensamiento de José Martí. De él se escogieron las cartas, por la interioridad espiritual que contienen y porque en los textos acerca de él no se destacan por haber sido objeto de estudio, ni bibliografía básica. Se delimitó como marco histórico el año 1895 (hasta su muerte, el 19 de 
mayo del mismo año) porque crece su consagración a la guerra de independencia de Cuba iniciada el 24 de febrero de ese año.

\section{Resultados de la investigación}

\section{La categoría sensibilidad humana. Aproximación a su delimitación teórica.}

Una de las raíces teóricas de este contenido es la categoría sensibilidad. En el empleo de esta sobresalen los nexos con el conocimiento. Dentro de los autores más antiguos que así la usan están Platón y Aristóteles. Una muestra de las ideas del primero son los vínculos que establece, en su teoría del alma, entre lo racional, lo irracional y lo concupiscible (Platón, 2011, p. 220), así como entre la razón y la sensación, como cuando asegura que en los objetos de esta última hay los que "no invitan a la inteligencia a examinarlos, por ser ya suficientemente juzgados por los sentidos; y otros, en cambio, que la invitan insistentemente a examinarlos, porque los sentidos no dan nada aceptable" (p. 289). De Aristóteles cabe señalar que desarrolla la categoría de referencia, entre otros momentos, cuando trata las impresiones, las acciones, los seres y los conocimientos sensibles (Aristóteles, 2011, pp. 307-339); de estos delimita como rasgo general que su adquisición es sin grandes esfuerzos y los considera inferiores al racional, pero no les resta importancia.

La atención a la sensibilidad ligada al conocimiento continuó después de Aristóteles. En ese andar descuella el siglo XVII con la delimitación de las líneas filosóficas racionalista (acentuación de la razón en dicho proceso; exponentes: Descartes, Spinoza) y empirista (el conocimiento se basa en la experiencia; niega las ideas espontáneas y el pensamiento a priori), donde se destaca John Locke (2011): "la experiencia: he allí el fundamento de todo nuestro saber" (p. 259).

La palabra sensibilidad, además de usarse relacionada con el conocimiento, se ha em- pleado con otros significados (ligados entre sí y con el anterior). Uno de ellos es la facultad de sentir, propia de los seres vivos, que en los humanos no se da inmediatamente, ya que los sentidos se transforman en la actividad, en su relación con los objetos humanos o humanizados, donde dejan de ser estrictamente biológicos y devienen medios de afirmación humana y de autoconocimiento; el ser humano se afirma como tal no solo con el pensamiento, sino con todos los sentidos (Marx, 1962, pp. 86-87). En este marco, no pocas veces se emplea la categoría sensibilidad humana para subrayar que es la capacidad humana de sentir, que se trata de la capacidad de sentir de los humanos y no de todo tipo de sensibilidad (Molina, 1997, p. 71), pero esto se infiere del discurso pues no hay elaboración teórica al respecto. En este mismo eje de significado suele hablarse de formas de sensibilidad; una de ellas se ve como específica y suprema, porque "expresa en toda su riqueza y plenitud la verdadera relación humana con el objeto como confirmación de las fuerzas esencialmente humanas en él objetivadas" (SánchezVázquez, 1990, p. 50): la estética. Pero también se habla de otros tipos de sensibilidad: política, económica, epistemológica, de una clase, de una época histórica, de una región, de los sexos (Montiel, 2000, p. 17; Ravelo, 1995, p. 58) o se relaciona con un ámbito del quehacer humano, por ejemplo, la educación y el conocimiento (Viegas-Fernandes, 2002, p. 8). Estos tópicos se tratan en una bibliografía abundante y variada; pero comúnmente solo se menciona la categoría, no se desarrolla teóricamente.

Otro empleo del vocablo sensibilidad es para referir la facultad de experimentar sensaciones, físicas o morales, a partir de causas externas o internas, que producen sentimientos y estados afectivos; no pocas veces se asocia a la piedad, la ternura y la religiosidad. Vale apuntar que la palabra sentimiento aparece en la filosofía francesa del siglo XVII y que con ella Descartes designa estados mentales ligados a las necesidades del organismo: el hambre, la sed, el dolor; los concibe como 
confusos, pasivos y dentro de la categoría $p a-$ siones (Maisonneuve, 1953, p. 2). En este siglo se forman tipos de concepciones acerca de los sentimientos: la metafísica, procedente de Pascal, según la cual son intuitivos y se asocian a los valores espirituales; la psicofisiológica, procedente de Malebranche, en ella son un estado irracional que traduce la reacción del sujeto a su medio y se acompaña de modificaciones corporales; la intelectualista, procedente de Leibniz, a su luz se tiende a concebirlos como una forma confusa de inteligencia (p. 5).

La atención a la sensibilidad y los sentimientos se mantiene posteriormente. En el siglo XVIII es mayor la preocupación por exaltar sus méritos que por esclarecer su esencia (Maisonneuve, 1953, p. 6); J. J. Rousseau (2012, p. 168) es uno de los autores que los destaca. En el siglo XIX y principios del siglo siguiente varios filósofos enriquecen la teoría dedicada a ellos, profundizan en sus formas y con frecuencia los fijan en la esfera de la sensibilidad; entre ellos está Victor Cousin, quien delimita las facultades del alma en: sensibilidad, inteligencia y voluntad. Esta división, que fue "popularizada por los Manuales de enseñanza, tiene el grave inconveniente de mutilar la realidad psíquica, señalando una autonomía ilusoria de las tres facciones" (Maisonneuve, 1953, p. 6). Una muestra de la presencia de este criterio es el filósofo cubano del siglo XIX Ramón Zambrana; para él la sensibilidad es reflejo del amor de Dios (Jardines, 2015, p. 37) y la asocia a los sentimientos.

Según el autor J. Maisonneuve (1953), la mayoría de los psicólogos de la primera mitad del siglo XX se interesó por los sentimientos $\mathrm{y}$ tomaron partido por su naturaleza mental o por su origen orgánico y junto a ello se pronunciaron en torno a la esencia de los estados afectivos en dos direcciones: la intelectualista (se derivan del conocimiento) y la psicológica (pueden existir fuera de la inteligencia, tienen su raíz en los instintos); apunta que en ningún caso se reparaba en su autonomía y que hasta entonces se solía identificar las palabras sen- timiento, emoción, estados afectivos y afecto; para delimitar, considera lo afectivo como el estadio interno del yo con sus tonalidades agradables y desagradables, opuesto a lo racional y a lo voluntario (pp. 7-9), y sugiere que el vocablo emoción se emplee para las formas más explosivas de lo afectivo y el de sentimiento para las serenas (p. 23). Mientras que el autor norteamericano Daniel Goleman (s.f.) señala que lo afectivo incluye a las demás categorías y que el estado afectivo perdura más que las emociones y es menos intenso que ellas (pp. 182-183).

Una interpretación adecuada debe: evitar que se determine en los sentimientos la función de lo corporal y lo espiritual "sin pretender reducir uno al otro. Considerará [...] el conjunto alma-cuerpo como unidad vivida, una de cuyas funciones es la afectividad" (Maisonneuve, 1953, p. 13); considerar que "así como dependen de factores causales y modificadores, también ejercen ellos causalidades o modificaciones en los demás contenidos psíquicos del Yo" (Laburu, 1946, p. 35); y no olvidar que "lo humano se constituye en el entrelazamiento de lo emocional con lo racional" (Maturana, 2001, p. 8).

La palabra sensibilidad tiene otro significado: la propiedad de los seres vivos de manifestar atracción o rechazo ante todo tipo de estímulos. Esta acepción es la raíz de la categoría sensibilidad humana, según se utiliza en el presente estudio. Su esencia radica en dos aspectos relacionados entre sí: primero, el sentir humano visto de modo complejo, como resultado de la integración de los sentimientos y la razón, así como de la conjugación dialéctica de estos con la sociedad; segundo, la reacción resultante y portadora de la mencionada integración y antítesis de la indiferencia y la pasividad.

Con la sensibilidad humana se quiere subrayar lo siguiente: todos los estímulos son importantes, aunque sean mínimos; ante los estímulos debe haber respuestas y deben atenderse; la integración razón-sentimientos se apoya en las características y exigencias de la 
sociedad y la época histórica; el adjetivo humana significa no solo que pertenece a los seres humanos, sino que estos son su esencia y fin; tiene una finalidad humanamente constructiva, por lo cual no bastan la piedad y la ternura, sino respuestas constructivas; el espíritu tolerante y comprensivo para no desencadenar violencia, sino solidaridad y ayuda.

Un antecedente teórico directo de esta concepción de sensibilidad humana es el concepto razón poética de la filósofa española María Zambrano (1939), quien lo sostuvo para referir la integración de la razón y los sentimientos como la vía, espiritual, para lograr la solución de los problemas del mundo que le tocó vivir (p. 20). Entre ambas concepciones hay un punto común: la mencionada integración, pero en la de la sensibilidad humana la pretensión integradora se encamina a destacar la importancia de todo estímulo y de las reacciones, con la finalidad de acabar con la indiferencia e incentivar el activismo social, que puede tener lugar no solo en lo político.

En este universo temático procede mencionar la concepción de inteligencia emocional del autor Daniel Goleman (s.f.) se basa en el vínculo entre los sentimientos, el carácter y los impulsos morales, así como en la relación entre las actitudes éticas y las capacidades emocionales subyacentes, ya que el impulso es el vehículo de la emoción y la semilla de todo impulso es un sentimiento expansivo que busca expresarse en la acción; por eso, quienes se hallan a merced de sus impulsos y carecen de autocontrol, adolecen de una deficiencia moral, porque la capacidad de controlar los impulsos constituye el fundamento mismo de la voluntad y del carácter (p. 6). Trata de armonizar la razón y los impulsos emocionales y para ello enfatiza la utilización inteligente de las emociones (p. 24).

Por eso, en sus ideas tienen un sitio significativo el entusiasmo, la perseverancia, la capacidad para motivarse a uno mismo y, sobre todo, el autocontrol. Entre las habilidades emocionales incluye: la conciencia de uno mismo; la capacidad para identificar, expresar y controlar los sentimientos y la habilidad de controlar los impulsos, que implica conocer las diferencias entre los sentimientos y las acciones, así como aprender a adoptar mejores decisiones emocionales, controlando los impulsos (Goleman, s.f., p. 164). La integración de las facultades humanas, su utilización compleja y el reconocimiento del autocontrol, son comunes a la comprensión de Goleman y a la que se defiende en este texto, pero esta última se contrapone a la autorrepresión y propugna el activismo social.

Ese espíritu integracionista está asimismo en otras comprensiones, como la que sostienen los autores R. Arias y V. Lemos (2015) en torno a la inteligencia espiritual, en la cual conjugan lo cognitivo, lo afectivo y lo conductual. Esta idea se aviene a la que sostiene el autor R. Bodei (1995), que quien quiera mantener los conceptos razón y pasión debe dejar de aprehenderla como una relación de lucha "entre lógica y ausencia de lógica [...] Se podrá interpretar esta relación, si acaso, como conflictividad entre dos lógicas complementarias" (p. 4). Otros autores han acentuado la correspondencia entre las emociones y la razón, así como la posibilidad y el beneficio de conjugarlas (Viegas, 2002, pp. 10-11).

Cercana a la concepción de sensibilidad humana que se defiende en este trabajo es la idea de sensibilidad de entorno (Wagensber, 1998, p. 10), que recalca la relación entre el individuo, su libertad y el entorno, sobre todo social, apoyado en el conocimiento de las condiciones objetivas y el correspondiente comportamiento humano como ser complejo; por eso alude momentos importantes: la intencionalidad, la construcción, la creatividad, la flexibilidad, entre otras, que siempre se responden a principios, propósitos, ideales, etcétera, de corte moral, social, político, económico. La sensibilidad de entorno refiere las relaciones entre las condiciones previsiblemente imprevisibles y las acciones 
humanas, pero no sostiene como propósito clave el de atacar la indiferencia y la insensibilidad.

Existen otras concepciones de la sensibilidad humana. Una de ellas es la que sostiene el autor Vicente Beltrán Anglada (2008), quien la despliega desde una perspectiva psicológica y a su luz argumenta cuatro tipos de sensibilidad: la mental, la emocional, la física y una apta para todos los humanos, pero que solo pueden utilizar quienes poseen una mente muy desarrollada y un corazón abierto a las necesidades sociales. La cuarta forma la identifica con la vida espiritual, cuya esencia es la religión.

Una parte considerable de las teorías estudiadas en este texto, sobre todo las más actuales, que no son la totalidad, tienen valía porque se encaminan de una u otra forma a hallar soluciones a los problemas de la humanidad, entre ellos la indiferencia, que hoy crece desmedidamente. Una manera de atacarla es mediante el aumento de la sensibilidad humana, que por lo cual es significativo el consumo de productos espirituales que la incitan, entre ellos los textos, no solo donde se reflexiona acerca de ella, sino los que la manifiestan o estimulan su presencia, como con los de José Martí.

\section{La sensibilidad humana en las car- tas de José Martí de 1895.}

\section{La integración sentimientos-razón en José Martí. Una mirada múltiple.}

En la concepción de sensibilidad humana que se defiende en este texto, el componente básico es la conjugación de los sentimientos y la razón. Este aspecto está presente en el pensamiento de José Martí. Emitir tal afirmación no es una novedad ya que no pocos autores la han destacado, no solo los más recientes, también los contemporáneos suyos.

Entre los pensadores que tuvieron amistad con él y que compartieron muchas de sus ideas, ante todo el patriotismo, tienen un sitio destacable los cubanos Manuel Sanguily (18481925) y Enrique José Varona (1849-1933).

De Manuel Sanguily con respecto a José Martí sobresalen los criterios que expone en dos discursos, uno pronunciado en los Estados Unidos el 10 de octubre de 1895, en conmemoración del inicio de la Guerra de Independencia de Cuba el 10 de octubre de 1868, y el otro, pronunciado el 19 de mayo de 1896 para conmemorar el primer aniversario de su muerte. En el primero, aunque parte de la capacidad racional martiana y la enfatiza, sobre todo en el quehacer revolucionario, muestra una visión integradora (similar a la de Martí), porque halla su gran merito en la conjugación de una serie de rasgos: "el caudal inagotable de sus ideas, en su fogosa imaginación, en su peculiar pero altísima oratoria, en sus aptitudes diversas y asombrosas" (1916a, p. 16). En el otro texto, Sanguily no se aleja mucho de la posición que había adoptado en su intervención anterior porque deja entrever en sus ideas que el sustento del espíritu revolucionario de Martí estaba en la integración de la razón y los sentimientos, no obstante, destaca la parte afectiva, sobre todo cuando señala que "se mantenían en el alma de Martí la exquisita susceptibilidad moral y política y las ansias torcedoras del patriotismo" (1916b, p. 33).

En cuanto a Enrique José Varona (1919) en sus consideraciones acerca de José Martí es destacable: el hombre en todas sus facetas. Pero sería una limitación si no se señalara que el propio Varona (1896) más de una vez destaca en Martí la conjugación de lo afectivo y lo racional. Una muestra de ello se ofrece en un discurso que pronuncia el 14 de marzo de 1896 en la Sociedad Literaria de Hispanoamérica, y lo hace al caracterizar físicamente al Apóstol de la independencia cubana: "Cuando se veía a Martí silencioso, la espaciosa y limpia frente decía inteligencia; los ojos dulces, profundos y melancólicos sobre toda ponderación decían arte" (1896, p. 6). Algo similar puede hallarse en otras reflexiones de Varona; una de ellas 
está centrada en sus cualidades intelectuales, donde también subraya la interacción sentimientos-razón: "De temperamento artístico, escritor copioso, orador apasionado y de brillante fantasía, era al mismo tiempo trabajador infatigable y hombre de carácter y de gran tenacidad de propósito" (p. 167). Otro ejemplo, se centra en la afirmación de Varona al decir que Martí razonaba las características y necesidades de la sociedad cubana con la finalidad de "buscar el corazón de todos los que viven en Cuba, con tal que amen a Cuba" (Varona, s.f., p. 149) y siempre que sea en aras de su independencia.

En Cuba, desde principios de la década de los 60 del siglo XX ha crecido sostenidamente la bibliografía acerca de Martí. En ella está presente dicha integración de varias maneras, entre ellas: centrada en su obra: "quería que la prosa recogiera el sentimiento con tanta fidelidad como la poesía, pero le pedía igual respeto y lealtad para [...] el pensamiento" (Iduarte, 2007, p. 118); vinculada a los destinos de Cuba: se afirma que sus ideas se afianzaron tanto en el amor a los humanos como en "el conocimiento científico que se ha de tener para la conducción de los procesos sociales" (Guadarrama, 1995, p. 11); o ligada al ser humano: "la unidad fundamental humana en Martí incluye todo el cosmos humano [...] como integridad digna de respeto, amor, sensibilidad y razón" (Pupo, 1998, p. 82). Estas últimas palabras ilustran, además, que no es una novedad referir la sensibilidad de Martí, no solo como poeta, porque al decir de algunos estudiosos es lo que le permite aprehender como nadie los conflictos humanos (Mendoza, 2008, p. 13).

Sobre esa base amerita puntualizar que lo novedoso de este texto está en mostrar la presencia de la sensibilidad humana en el pensamiento martiano, lo cual incluye evidenciar no solo la conjugación sentimientos-razón, también la atención a los detalles y la emisión de respuestas, las cuales son en sí anulación de la insensibilidad, de la indiferencia.

\section{La guerra cubana de 1895 en la sensibilidad humana de José Martí.}

La sensibilidad humana en Martí (1975) se afianza sobre una concepción filosófica basada en la comprensión unitaria del universo (Tomo 19, p. 299) y la naturaleza: "todo lo que existe, en toda forma - espíritus y cuerpos" ( $p$. 364) y se orienta por la unidad formada por "la verdad: que es la hermosura en el juicio; la bondad, que es la hermosura en los afectos; y la mera belleza, que es la hermosura en el arte" (Tomo 13, p. 25). Aunque en esta guía sobresale lo afectivo, que destaca no pocas veces, como al decir que "por el amor se ve. Con el amor se ve" (Tomo 21, p. 419), no lo sobrevalora, porque no le resta importancia a lo racional, antes bien, los conjuga, como muestra con frecuencia en muchos de sus textos.

Apoyado en ese cimiento, en las cartas de 1895 sobresale su relación con la patria y su independencia como una constante «raciosentimental», de ello da fe no pocas veces, como al decir que su revolución es "toda amor y cemento, toda previsión y piedad" (Tomo 4, p. 60). Con respecto a la obra revolucionaria, piensa primorosamente para que no tuviera lugar ni "imprevisión, ni esperanzas fantásticas" ( $p$. 45). Esta constante la aplica a todos los aspectos, aunque parezcan insignificantes, si tienen algún vínculo con la soberanía de Cuba. Pero sus palabras no solo llevan razón y sentimiento, también acción, y no porque son órdenes; antes bien, sugieren, orientan, invitan a tomar conciencia, a eliminar la indiferencia y a actuar. Todo su pensamiento evidencia estas cualidades, a veces de modo directo, por ejemplo, cuando afirma que "hacer, es el único modo eficaz de responder. Sólo empujan el ejemplo y el éxito" (p. 65).

De la obra revolucionaria en el pensamiento martiano amerita destacar cuatro aspectos: es una decisión que toma en sus años mozos para toda la vida, a partir de las condiciones objetivas internas y externas; abarca dos 
etapas: la guerra de independencia de 1895 y el período posterior al triunfo; en ambos períodos la finalidad es el beneficio de sus protagonistas, los cubanos; en ella es crucial el peso del calor humano.

Por eso sostiene que para llevarla adelante no bastaba la razón; los sentimientos eran imprescindibles y concibe su organización con consciencia, pero también con respeto, amabilidad y cariño. Este último es un principio y un medio de su accionar mental y práctico. De esto hay muchas evidencias en su toda obra escrita; una de ellas es cuando refiere la "dulzura que da la compañía cariñosa en las cosas difíciles" (Tomo 20, p. 482).

Con respecto a los participantes en la revolución, su objetivo es diáfano: sumar fuerzas y consolidar la unidad (Tomo 4, p. 60); a este propósito enlaza el cariño, que destaca en los emigrados, tanto el de ellos hacia la revolución, como el que se ganaban por su comportamiento e ideas, y afirma: "Yo ato en haz aún más fuerte las emigraciones conmovidas y cariñosas, más cariñosas hoy que nunca" (p. 21). Sobre esta base hace saber que junto a él "todo se encariña y unifica" (p. 121), por lo cual siente "alrededor cariño justo" (p. 36), o sea, no solo afectuoso, también razonable.

Martí (1975) insiste en la unidad en la lucha revolucionaria y en que de ella no podía ausentarse la calidez humana; por eso elogia la "unanimidad de corazón, qué respeto al esfuerzo, qué gozo en el propio sacrificio, el de las emigraciones de hoy" (Tomo 4, p. 74). Pero al mismo tiempo exhorta que no obstante la premura de la obra independentista, había que hacerla con cuidado, con "moderación [...] el olvido sincero de toda provocación o diferencia, sin entregar por eso la casa" (p. 73). Nada era superior a la independencia, ni las tácticas de la propia lucha por alcanzarla. Recomienda: trabajar con quien aún es indiferente, para incorporarlo a la lucha; comprometer a quien todavía vacila; estimular el entusiasmo general y concienciar a todos para que ayudaran en la obra revolucionaria (pp. 75-77) y cuando esta ya marchara, se le pediría la contribución "de hermano a cada hijo de América" (p. 77). Todo esto es muestra de sensibilidad humana.

Con el propósito de comenzar las acciones bélicas en el momento más oportuno, en el mes de enero atiende con mayor insistencia la situación interna de Cuba, aunque no olvida la externa y asegura que "demoras y escarceos ahora son verdaderos crímenes" (Tomo 4, p. 26). De modo implícito subraya que para triunfar había que tener en cuenta todo, incluido lo aparentemente insignificante, porque a veces una pequeñez deshace obras grandes (p. 47). No escapan de su atención las exigencias ni los peligros de la guerra (p. 27), ni las fuerzas organizadas fuera de Cuba y mucho menos sus sentimientos, porque ellos constituían el corazón cubano en el exterior (p. 72).

Muestra de la sensibilidad humana son las siguientes recomendaciones que ofrece a los revolucionarios: no perder de vista el cariño que ha de existir entre todos los cubanos (Tomo 4, p. 60), ni la firmeza, el orden y "la nobleza con que se juntan, sin más idea que el bien patrio inmediato y entero, las fuerzas diversas, viejas y nuevas de la revolución" (p. 130); perdonar a los que se arrepienten, pero no descuidar que con la piedad "inmoderada suele entrar, en los hombres y en los pueblos, la desdicha" (p. 65).

En tanto respuesta que brota de la conjugación de la razón y los sentimientos, la sensibilidad humana condiciona un rasgo de suma importancia para la guerra: el carácter previsor: "todo lo necesario para hacer en cualquier forma, en una u otra forma, -lo que debemos y podemos hacer-, lo llevo hecho, completo, para ahora y para luego" (Tomo 4, p. 61). Pero al mismo tiempo le facilita otra gran cualidad: no adelantarse a los acontecimientos. Sobre esta base, considera incorrecto dar detalles antes de tiempo, como cuando después de comentar lo que posiblemente iba a suceder al 
día siguiente, asevera: “¿A qué minuciosidades, e instrucciones nulas, a tanta distancia?" (p. 59).

Para Martí (1975) "la patria, no será nunca triunfo, sino agonía y deber" (Tomo 4, p. 111), por eso sostiene que había que "dar respeto y sentido humano y amable, al sacrificio" (p. 111), posición que puede entenderse en su justa dimensión si se interioriza que en aras de la patria estaba dispuesto a sufrir y que concibe esta entrega como su consagración al bien ajeno. Aquí puede pensarse que su propósito se fundamenta solo en sentimientos y no es así; él mismo asevera que a Cuba "llevo un espíritu tan emancipado de la pasión, que solo lo erguiré, [...] cuando de su concesión [...] viera yo sinceramente algún peligro para la patria" (p. 117), aunque no descarta que en algún momento se impongan a lo racional, si de la patria se trata.

Con la mirada atenta a la revolución, su sensibilidad humana se muestra ante algunas de las características de los hombres que toman parte en la contienda. La fidelidad, el entusiasmo, la discreción, la audacia, el ímpetu son algunas de ellas, así como aptitudes físicas imprescindibles para las faenas militares: la fuerza, la agilidad, la resistencia. Alerta para que la flojedad y la vacilación no debiliten la disciplina ni la fe (Tomo 4, p. 25).

Uno de los hombres que más motiva su sensibilidad humana en este período es Gonzalo de Quesada, "más noble cada día; y limpio ya, a pesar de sus años jóvenes, de las tentaciones que a hombres de menos grandeza natural hubieran podido afearle el carácter" (Tomo 4, p. 47), formado por el sentido de deber, la modestia y la lealtad. Similar ocurre con José Miró, que no era cubano de nacimiento. A él le reconoce la pasión por la libertad de una tierra que mira como suya, y las cualidades que le han permitido llegar a ser uno de quienes se sacrifica por el bien común, que "solo nos da por premio verdadero [...] la fuerza y consuelo del cariño de los hombres capaces de entendernos y amarnos" (p. 162) y asegura que era de esos hombres quienes ponen su fuerza al servicio de la patria y "unen la grandeza que jamás pone precio a sus servicios" (p. 163).

En las cartas de 1895, la sensibilidad humana de Martí (1975) se muestra cuando considera especiales a algunos hombres porque han revelado la capacidad para razonar por sí solos con la participación de los sentimientos, pero le brinda un valor mayor cuando esta juntura se enfila hacia el beneficio de los demás seres humanos y la patria. Una demostración de ello es cuando al caracterizar a un amigo, dice que es de esos que "saben mirar desde ellos, y sienten con entraña de nación, o de humanidad" (Tomo 4, p. 110). Es evidente el énfasis en las acciones revolucionarias, en los detalles y en la anulación de la indiferencia.

La sensibilidad humana más allá de la guerra necesaria. Desde los años mozos la revolución y la patria están en las entrañas espirituales de José Martí (1975); en 1895 redobla su atención y entrega a ambas, por eso pudiera pensarse que entonces su sensibilidad humana se debe solo a ellas, pero no es así; una muestra está en la carta que le escribe a su madre el 25 de marzo, donde despliega amor razonado y de razonamiento amoroso al decirle: "No son inútiles la verdad y la ternura" (Tomo 20, p. 475).

Durante esos meses no desaparecen los recuerdos; en ellos los amigos tienen un espacio especial, sobre todo aquellos a quienes evoca "por bravos, por sensatos, por su radical y generoso pensamiento" (Tomo 4, p. 166). En su remembranza conjuga la razón y los sentimientos y la destaca en quienes rememora, vinculada a las acciones basadas en el amor a la virtud y el sacrificio; así afirma que de los sentimientos "ninguno es más bello que la simpatía de las ideas generosas" (p. 142), y le encomienda a un amigo conocer a Gonzalo de Quesada, para que estime a "un joven que es como hijo íntimo mío, más que el mío propio, 
porque más me acompaña y ayuda, en mi afán porque Cuba sea al fin tierra de honor" (p. 51); y le pide que le muestre cariño porque posee un espíritu transparente. Al propio Gonzalo le comenta la fuerza que obtiene de su amistad para enfrentarse a la insensibilidad que lo rodea, por eso cree y siente con vehemencia que "hay que ir levantando fortalezas de cariño" (p. 58).

La carga sentimental de los razonamientos de José Martí y la fuerza racional de los sentimientos que recorren e impulsan su pensamiento, constituyen un ejemplo a tener en cuenta para impedir o limitar la frialdad que actualmente se apodera cada vez más de los seres humanos y para avanzar en su mejoramiento y en el aumento de sus libertades.

\section{Conclusiones}

El incremento de la predilección por lo banal y por los bienes materiales, así como de la indiferencia a los problemas humanos, evidencian la necesidad de redoblar desde todas las perspectivas, sobre todo la educacional, la atención al universo espiritual. Pero esta tarea no puede limitarse al enriquecimiento de dicho universo mediante el consumo de productos espirituales (artísticos, filosóficos, entre otros), ni es suficiente el estímulo de la sensibilidad, entendida como capacidad de sentir de los seres vivos y ligada a la afectividad. Tal situación social exige miradas diferentes.

A la anterior exigencia responde la formulación de la categoría sensibilidad humana porque con ella se enfatiza la conjugación sentimientos-razón y las respuestas desde ella y con ella, a todo tipo de estímulo, para enriquecer el universo espiritual y atacar la indolencia ante los problemas de la humanidad. Un medio para incitar la sensibilidad humana son los textos donde se trabaja teóricamente o se estimula.

En las cartas que José Martí redacta en los meses que vive del año 1895 las muestras de sensibilidad humana se relacionan con aspectos claves de la guerra de independencia de Cuba, sobre todo con la unidad de las fuerzas revolucionarias; no obstante, no se ausentan otros aspectos de la vida, como la amistad, y subraya como misión el mejoramiento de los seres humanos y el incremento de sus grados de libertad.

\section{Referencias}

Arias, R., \& Lemos, V. (2015). Una aproximación teórica y empírica al constructo de inteligencia espiritual. Enfoques, 27(1), 79-102.

Aristóteles. (2011). Metafísica. En R. M. BuchSánchez (Ed.), Antología. Historia de la filosofia (Tomo 1) (pp. 306-490). La Habana: Editorial Félix Varela.

Beltrán, V. (2008). Conversaciones esotéricas. Asociación Vicente Beltrán Anglada. Recuperado de http://www.asociacionvicentebeltrananglada.org .

Bodei, R. (1995). Geometría de las pasiones. México: Fondo de Cultura Económica.

Díez, J. (2011). ¿Regreso a los valores materialistas? Revista Española de Sociología, 15, 9-46.

Espinal, C., Estrada, D., \& Pérez, L. (2012). Una aproximación a la anorexia desde el discurso fenomenológico. Revista Colombiana de Sociología, 35(2), 183-193.

Goleman, D. (s.f.). Inteligencia Emocional. Recuperado de www.capitalemocional.com

Guadarrama, P. (1995). Martí dentro del concepto latinoamericano de humanismo. Revolución y cultura, 3, 11-15.

Iduarte, A. (2007). [Ideas] Estéticas de José Martí (Fragmentos). En, Valoración múltiple 
(Tomo 2) (pp. 118-125). La Habana: Fondo Editorial de la Casa de las Américas.

Jardines, A. (2015). Filosofia cubana in nuce. Madrid: Hypermedia Ediciones.

Laburu, J. A. (1946). Los sentimientos. Su influjo en la conducta del hombre. Montevideo: Editorial Mosca Hrnos. S. C.

Lardellier, P. (2014). El liberalismo a la conquista del amor. Revista de Sociología de la Universidad de Chile, 29, 77-87.

Locke, J. (2011). Ensayo sobre el entendimiento humano. En R. M. Buch-Sánchez (Ed.), Antología. Historia de la filosofía (Tomo 3) (pp. 256-262). La Habana: Editorial Félix Varela.

Maisonneuve, J. (1953). Los sentimientos. Barcelona-Madrid: Salvat Editores.

Martí, J. (1975). Obras Completas. La Habana: Editorial de Ciencias Sociales.

Marx, C. (1962). Manuscritos económicofilosóficos de 1844. México: Grijalbo.

Maturana, H. (2001). Emociones y lenguaje. Santiago de Chile: Ediciones Dolmen Ensayo.

Mendoza, L. (2008). Cultura y valores en José Martí. La Habana: Pueblo y Educación.

Molina, M. (1997). Juventud y valores: ¿Crisis, desorientación, cambio? Temas, 15, 65-73.

Montiel, E. (2000). Globalización y geopolíticas de las culturas. Temas, 20-21, 12-17.

Platón. (2011). La República. En R. M. BuchSánchez (Ed.), Antología. Historia de la filosofia (Tomo 1) (pp. 123-305). La Habana: Editorial Félix Varela.
Pupo, R. (1998). Aprehensión martiana en Juan Marinello. La Habana: Academia.

Ravelo C., P. (1995). Posmodernidad y marxismo en Cuba. Temas, 3, 58-68.

Retana, C. (2014). Sociología de la moda. Revista Mexicana de Sociología, 2, 324-327.

Rousseau, J. J. (2012). Discurso sobre el origen de la desigualdad. En T. S. Iglesias (Ed.), Antología. Historia de la filosofia (Tomo 4) (pp. 165-172). La Habana: Editorial Félix Varela.

Sánchez-Vázquez, A. (1990). Las ideas estéticas de Marx. La Habana: Pueblo y Educación.

Sanguily, M. (1916a). Céspedes y Martí. En Biblioteca Cuba 2, Frente al enemigo (Vol. 2) (pp. 5-28). La Habana: Imprenta Artística 'Comedia.'

Sanguily, M. (1916b). José Martí y la Revolución Cubana. En Biblioteca Cuba 2, Frente al enemigo (Vol. 2) (pp. 29-64). Habana: Imprenta Artística 'Comedia.'

Varona, E. J. (Ed.) (s.f.). Primer aniversario. Patria, Nueva York, 20 de mayo de 1896. En, Artículos periodísticos (pp. 147-150).

Varona, E. J. (1896). Martí y su obra política. New York: S. Figueroa Editor.

Varona, E. J. (1919). El primer año de la Revolución. En Enrique José Varona (Ed.), De la colonia a la república (pp. 161-179). Habana: Sociedad Editorial Cubana Contemporánea.

Venegas, M. (2011). Un modelo sociológico para investigar las relaciones afectivosexuales. Revista Mexicana de Sociología, 73(4), 559-589. 
Viegas-Fernandes, J. (2002). La educación que necesitamos. Temas, 31, 4-17.

Wagensber, J.(1998). Ideas sobre la complejidad del mundo. Barcelona: Tusquets.

Zambrano, M. (1939). Pensamiento y poesía en la vida española. México: Fondo de Cultura Económica. 